\title{
ACTIVIST DESIRE, CULTURAL CRITICISM, AND THE SITUATIONIST INTERNATIONAL
}

\author{
David Banash
}

Theory cannot prolong the moment its critique depended on. A practice indefinitely delayed is no longer the forum for appeals against self-satisfied speculation; it is mostly the pretext used by authorities to choke, as vain, whatever critical thoughts the practical change would require. -Adorno

In the world of Anglo-American criticism, Situationism was once the province of hip theorists, progressive art historians, and a few scattered Marxists. No more, for the nineties have seen Situationism come from obscure movement to the defiant avant of our cultural-critical-garde. Not only has the past decade seen the publication of a dozen books, countless articles, dissertations, and both academic and activist web-sites, the Situationists have moved right into the main line of pop-culture. Situationist graffiti turns up as the epigraph for gen-xer Elizabeth Wurtzel's Bitch: In Praise of Difficult Women, and, with Rolling Stone darling Greil Marcus's Lipstick Traces: A Secret History of the Twentieth Century, it has become the official prototype of punk aesthetics. However, there is more at stake in our specifically academic recuperation of Situationism than the disinterring and popularizing of yet another corpse to feed the machine with books, articles, and conference papers. Rather, Situationism's reception is dominated by a will to make the political desires of cultural criticism coincide with immediate material practice.

In this paper, I will first situate our reception of the SI in the context of cultural criticism, demonstrating how contemporary critics mobilize the SI to underwrite their activist agenda. Second, I will consider the tense relationship between theory and practice that constantly frustrated the SI itself. Finally, taking Debord's and Jorn's Memoires as a specific example, I will suggest that our current reception of the SI has occluded the vital role of 
theory as a condition of possibility for activism. In short, I will read the SI against both its own articulation and our current reception in order to interrogate the one-dimensional sense of practice which animates and frustrates the SI and contemporary cultural criticism.

\section{Theory, Cultural Criticism, and the Resurrection of the SI}

The ethos that defines the Situationists seems at one with the currents of cultural criticism. The Situationists staked their claims to authenticity and efficacy on a seamless relationship between the practices of everyday life and theory. For their part, most cultural critics are at pains to align their work with progressive political projects that focus on the recognition and legitimation of differences which they advocate in the hope of transforming the reactive and residually patriarchal, elitist, commodified, and generally oppressive structures of power that continue to animate latecapitalism even at its most postmodern extremes. While cultural criticism rarely calls for revolution in the sense that the Situationists understood the idea, its claims to legitimacy are located in precisely the same rhetorical move: the value of any theory must be assessed by its potential to be aligned with an immediate and transformative political practice.

"Watch Out for Manipulators, Watch out for Bureaucrats" was the slogan of the Situationists in ' 68 as they struggled to realize the revolution in the face of reactionary desires on all sides. Today, unlike many other Situationist slogans, this one has been taken to heart by the Anglo-American critics. Consider Terry Eagleton's position on postmodernism and its relationship to theory. According to Eagleton, poststructuralism is simply a displacement of the revolutionary desires of left oriented groups like the Situationists into the safe and thoroughly bourgeois confines of universities and publishing: "Post-structuralism, which emerged in oblique ways from the political ferment of the late 1960s and early 1970s, and which like some repentant militant became gradually depoliticized ... has been among other things a way of keeping warm at the level of discourse a political culture which had been flushed off the streets" (25). No doubt when Eagleton says that politics were taken off the streets he is referring to the failures of " 68 . In this reading, poststructuralism is simply the defeated and impotent heir of the Situationists.

For Eagleton, a committed Marxist, this is the great failure of both the Situationists and theory as a whole. While theory does provide a space for revolutionary desire, it also confines that desire. Would-be revolutionaries become the manipulators and bureaucrats of academic institutions because they cannot translate theory into an instrumental revolutionary force. As Eagleton puts it, left to the theorists "the power of capital" will remain "so drearily familiar" that those who espouse its critique or transformation only "succeeded in naturalizing it" (23). Thus, for Eagleton, critics must develop "strong ethical and even anthropological foundations" that could provide "the political resources" required to maintain a resistance aligned 
with a recognizable transformation of the system. Given Eagleton's Marxist position, there is nothing surprising in his critique of poststructuralism's seeming inability to actualize political change. What is far more interesting is that Eagleton's position is repeated and developed even more strenuously by cultural critics with stronger allegiances to poststructuralism.

In their book Postmodern Theory: Critical Interrogations, Best and Kellner argue that the value of any theory is the possibility it offers to actualize "radical social transformation" (298). Like Eagleton, Best and Kellner argue that theory must develop an immediate relationship to practice or remain "just another specialized discourse" whose members accumulate cultural capital and theorize "just for the fun of it" (298). In essence, theorists become, again, manipulators and bureaucrats serving only their own reactionary interests. The problem of theory's relationship to practice is embedded in the many articulations of cultural criticism's project, and, as we shall see, it is precisely these urgencies that have powered the resurrection of the SI.

The legitimation of cultural criticism by instrumental politics is, according to Robert Con Davis and Ronald Schliefer, precisely what defines it as a project, for it is "understanding" that leads to the "power of transformation" which "cultural studies offers" (679). This transformation - the active and practical politics that cultural studies promotes - is often set in opposition to the perceived hermeticism of poststructuralism which, according to David Bathrick's summary of the argument, is seen as precisely "the forfeiture of any position" from which a critic could offer "readings, meanings, or value judgments" (327). Though cultural critics often rely on poststructuralist strategies, poststructuralism itself is cast as a hermetic and apolitical discourse. The urgency critics feel to reconcile this perceived divide between theory and practice is made clear in Michael Bérubé's position. According to Bérubé, the most urgent challenge to critics is to undertake the work of translation: "cultural studies, if it is going to be anything more than just one more intellectual paradigm for the reading of literary and cultural texts, must direct its attention to the local and national machinery of public policy" (224).

If, at the end of the nineties, there is one overriding urgency for cultural studies, it is, without a doubt, that of translating the intellectual work of scholars into instrumental politics. For many critics, then, it only makes sense to turn to the work of Guy Debord and the Situationists. Consider that articles and books on the SI are almost invariably scattered with gritty blackand-white photos from the events of May '68: cars overturned, students hurling stones, shop windows broken, members of the SI in meetings of the occupation committee. This is the image that sells the SI in its current academic commodification -theoretically sophisticated revolutionaries who gave up their desks and typewriters to spray paint the walls and put theory into practice for a total revolution. Though few critics are likely to pick up stones anytime soon, the image is undeniably persuasive after more than a 
decade of blistering attacks against the quietism of theory and the continual erosion of an efficacious political left.

Scholars working on the SI have spent the decade scrambling to mobilize the Situationists as just the escape cultural critics need from such perceived quietism. As Sadie Plant argues in "The Situationist International: A Case of Spectacular Neglect," the reception of the Situationist legacy must align itself with forms of radical political intervention: "as long as those who do involve themselves in such discussions [e.g. the institutional reception of the SI in universities, museums, etc.] continue to engage in the subversions they promote in theory, the problems of a Situationist industry akin to that surrounding Marxism are easy to avoid" (Home 169). Plant's cautionary tone for would-be postmodern pro-situs is reiterated again and again. In the forward to the catalog for the 1996 exhibition of Situationist works on urbanism presented by the Museum of Contemporary Art in Barcelona, museum director Miquel Molins argues that the Situationists are "absolutely relevant today because of [their] interest in bringing culture and politics together, for having lucidly interpreted the transformation of a society devoted to material consumption" (9). For Molins, the exhibition is important insofar as it focuses on works that "reclaimed public space as a locus of cultural creation and political action" (9). It is precisely the hope that the Situationists might offer a way to translate the desires of criticism into instrumental effects which is reiterated by T. J. Clark and Donald NicholsonSmith. The title of their article really says it all: "Why Art Can't Kill the Situationist International." Of course it can't kill the Situationists because, Clark and Nicholson-Smith argue, the Situationists were ultimately political. And, today, what the Situationists offer is not simply an opportunity for art historians. Rather, "sooner or later the history of the S.I. is bound to serve in the construction of a new project of resistance. The sooner the better; there is no reason to think the moment will be long coming" (30).

Even those books which do not directly deal with the activist politics of the Situationists demonstrate that these concerns coordinate every facet of our contemporary critical reception. For instance, in his introduction to The Situationist City, Simon Sadler makes a nod toward just this preoccupation: "I rummage with a sense of guilt: situationists did not want to be just another avant-garde" (1). As he notes the quietist orientation of his study, he recognizes that "this plain fact will serve to damn it" among "the radicals who have carried the candle for situationist ideas since the demise of the Situationist International" (1).

These performances of scholarly self-loathing and the angry, often paranoid calls to action are most clear in the furor over Greil Marcus's Lipstick Traces. At best, critics like Bob Black have called the book "disorganized" and "uncritical" (Home 148). Or, as Andrew Ross would have it, Marcus's book is itself simply a "situation without a future," and thus the best hope for the book is that it will spur more serious critics to give their attention to the "new revolutionary arena" that the Situationist focus on 
commodity culture makes possible (114). Demonstrating that this is by far the most frequent critique of Marcus, Alaister Bonnett argues that Marcus reduced the SI to a depoliticized image of "desperate extremism" in which "political ideas are marginalized"(Home 194). Or, take Thomas F.

McDonough's strikingly similar position, arguing that Marcus's book has essentially depoliticized the SI not through the omission of the SI's political activism, but, even more shockingly, through the omission of their attempts in art, literature, and theory to develop the traditions of the historical avantgarde by reinventing it:

The crucial point is that throughout its history, the S.I. was engaged in a struggle over the possible meanings of culture, as over the legacy of the historical avant-garde, with a broad spectrum of postwar cultural producers. The Situationists participated in this struggle . . . it has been our inability to grasp this central fact that has allowed the S.I. to be assimilated into Greil Marcus's "secret history of the twentieth century," in which it becomes merely another irruption of millenarian transgression, reduced to the level of Punk's nihilism. (13)

Between Bonnett and McDonough we can see the two great mistakes Marcus has apparently made. On the one hand, he has separated the Situationists from their grounding in immediate and transformative activism. On the other hand, he has dehistoricized the SI, severing their work from a context in which we might hope to understand how they affected struggles over culture or how we might evaluate their ultimate successes and failures. In both of these takes on Marcus, the real attack seems to be that Lipstick Traces somehow removes the SI from its immediate grounding in practice, whether that practice is the ferment of revolution or the instrumental, though artistic, contestation of culture.

Given the agenda of critics looking for a means to empower theory in concrete and recognizable registers, these attacks on Marcus make a great deal of sense, but they do more to reveal the insecurities of critics than engage Marcus's most provocative points, so much so that we might wonder if these critics lack the ears to hear Marcus. After all, for all the charges made against him, few critics have been able to articulate Marcus's project as anything more than an ahistorical or nihilistic romp, and isn't it interesting how those particular charges echo the two most often repeated and reactionary responses to theory in general? However, maybe Marcus is onto something, something that many just aren't willing to hear. This something is, as I shall argue, caught up with the overwhelming instrumental failures of the SI in practice, their success in theory, and the implications of this for those who would position the SI as the example of committed theory through the total coincidence of theory and activism.

\section{The Articulation of the Untimely: The SI in Theory and Practice}

The easy way to make Marcus look like a popularizing lightweight 
is simply to quote the following (which in the reviews everyone does): is it a mistake to confuse the Sex Pistols' moment with a major event in history-and what is history anyway? Is history simply a matter of events that leave behind those things that can be weighed and measured-new institutions, new maps, new rulers, new winners and losers-or is it also the result of moments that seem to leave nothing behind, nothing but the mystery of spectral connections between people long separated by place and time, but somehow speaking the same language?

As we have seen, the response to this question has been less than enthusiastic. After all, the question does seem poorly put — devoid of political sensibility and commitment. However, consider what Marcus has to say just a few sentences later: "If the language they are speaking, the impulse they are voicing, has its own history, might it not tell a very different story than the one we've been hearing all our lives?" (4). Here is the punch line to that awkward beginning. Marcus's project is to write the history of an impulse, a desire that has not yet been realized, and this is surely not quite the kind of historicism that cultural critics in general really know what to do with. This is not a history of perceptible changes at the centers or the margins, for that would be the story we have been listening to all along. The Sex Pistols and the Situationists do not present us with a blueprint of the revolution but the trace of a desire for a world they couldn't realize. And, as Marcus notes, there is no expression of that desire outside the albums of the former and the theory of the latter. Taken through Nietzsche, Marcus's reading of the SI as an instance of the untimely is the most persuasive and useful reading of the SI we have, for it severs both the SI from its own frustrated pretensions to practice and our own tendency towards its specious recuperation. Marcus reminds us that the SI did fail on a consistent basis to realize in practice what it achieved in theory. Thus the SI is not an example of activism we should seek to emulate, but a story of theory's necessity in a world where alterian desires cannot yet express themselves through instrumental practice.

The point that I am trying to make here was suggested to me (and far more pivotally articulated) by Paul Trembath in his article "Reactivating Deleuze: Critical Affects After Cultural Materialism." According to Trembath,

what is devalued by current criticism (and in no sense deliberately, but rather reactively, implicitly) is any way of reading the world that moves astray from the explicit subject areas and goals that encode current critical rhetoric ... articles, conference papers, dissertations and books that foreground gender, race, sexual orientation, etc. as their subjects, and which seek the enhanced cultural enablement of differences of this recognizable sort as their practical goals. These subjects and goals are of unquestionable importance to critical pedagogy and progressive politics. In the estimate of this reader, only an uncritical reactionary of the worst kind would be "against" 
these subjects and goals, or oppose the practical politics with which they aim to coincide. What Deleuze reminds us, however, is that theory can do other things than transform itself dutifully into common-sensical language and practical alterian politics. Theory can also, in addition to pursuing instrumental goals, and perhaps at the same time, invent or pre-form new "sense" altogether, and move at speeds different from those compatible with the going quotidian or academic instrumentation. (2)

Trembath makes a point that both contemporary critics and the Situationists themselves often occlude -that sometimes theory is the only practice possible, that the sense it creates can overreach the limits of given material possibilities. This is not to say that theory is opposed to instrumental political activism, but it is to say that theory can challenge those limits, creating an untimely sense for practices yet to come. While theory can coincide with activism, it is also a space for the untimely, often the only space; to devalue that space is to separate theory from what it can do, and thus, as Adorno puts it, "choke, as vain, whatever critical thoughts the practical change would require" (3).

The Situationists did not succeed in realizing a practice coextensive with their theory. To act as though they had is dangerous for two reasons. First, it assumes that aligning theory and practice is a problem that they solved. Second, it devalues a significant aspect of theory's power for both their moment and our own.

For all the activist rhetoric that now surrounds our reception of the Situationists, the revolutionary experiment of transforming the modes in which alienated subjects of the spectacle experience themselves consists in two theoretical strategies: psychogeography and détournement. The most important aspect of psychogeography is the dérive. According to the SI, the dérive is "a mode of experimental behavior linked to the conditions of urban society: a technique of transient passage through varied ambiences"

(Blazwick 22). Here, the SI takes on the spectacle in its own territory, urban centers devoted to the commodity. Rather than experiencing such an environment in the alienated terms of the spectacle, the drifter uses this environment to generate the intensities of the constructed situation. Similar to the dérive, and far more pervasive in the works of the SI, is the textual practice of détournement. Just as the dérive cuts up a city into a set of chance encounters that force the drifter to assume an active role unmediated by spectacular images, détournement literally cuts up the totality of culture to produce the chance encounters, unexpected arrangements, and active senses associated with the dérive.

As Sadie Plant notes in her book The Most Radical Gesture: The Situationist International in a Postmodern Age, "détournement characterized the upsetting of relationships with people, cities, and ideas with games, dérives and constructed situations" (89). For Plant, both détournement and the dérive highlight the "sense in which the situationists conceived the social 
revolution: a gigantic turning around of the existing social world" (89).

However, both these strategies are finally theoretical. Neither the experience of drifting (and its translation into a psychogeographical map) nor the razoring and pasting of collage does a practical revolution make, though both certainly have a role in underwriting the critical sense necessary for revolution. Still, these two strategies hardly justify Plants claim that Situationist theory is only made possible by "acts of rebellion, subversion, and negation" (xi). In this, Plant echos the Situationist claim that "the theoretical critique of world power is inseparable from a practice that destroys it" (Knabb 171). Though strategies of détournement and psychogeography certainly contribute to the creation of alternative senses and desires, the past thirty years have shown that the Situationist project was carried out and still survives only as theory. Perhaps the SI got closer to this truth when, in "Détournement as Negation and Prelude," they stated that "we are partisans for a certain future of culture, of life. Situationist activity is a definite craft we are not yet practicing" (Knabb 55).

Though many critics would admit that psychogeography and détournement are basically theoretical, their trump card remains the events of May '68. For instance, Len Bracken argues that contemporary "revolutionaries will look to Debord's theories and the way he embodied his thought in May '68," thus assuming, of course, that Debord actually did embody Situationist theory in practice (239). If contemporary critics read the Situationist project as creating a lived relationship that would at every step actualize its theoretical possibilities in concretized practice, such a move is based as much on the SI's own claims as on a simplistic and unexamined response to the events of ' 68 . In the case of the former, the SI's attitude is so pervasive as to be almost beyond citation. Openly stated, or hovering as an a priori assumption in most of the SI's texts, is the notion that "radical theory must be prevented from being dealt with by speculation . . . knowledge is inseparable from the use that is made of it" (Knabb 169). Or, as Debord would have it, "revolution is not showing life to people, but making them live" (Bracken vii). However, to call the SI's project, even at its most active in '68, an alignment between theory and anything resembling a recognizable practice, and to locate the SI's value in such a move, seems a specious argument even for the SI itself. At points, SI texts seem to confirm this.

In an internal SI text dated 1970, Paolo Salvadori argues that before the SI can hope to actualize its theory in practice they must edit and rewrite a comprehensive account of that theory: "theory must first of all be put in a condition it which it can be effectively disseminated. The first step of theory's advance toward practice takes place within theory itself. The dissemination of theory is thus inseparable from its development" (Knabb 357). On the verge of its dissolution, there was a recognition within the SI that, given the goals of their project, theory and its dissemination to a mass audience remained the condition of possibility for practical actualization.

The entire Situationist project centers around the problems of 
developing a sense that operates without spectacular mediation. The SI is caught between the need to realize in practice what in their own formulations remains only the untimely possibility of alternatives that cannot yet be thought and lived by a significant number of people; thus their project remains only a vague possibility, incompletely articulated —a possible future yet to come. It is the hook of this irony that frustrated the SI's hopes for the May ' 68 revolution, and it is the events of May ' 68 that are often invoked by critics to justify their activist readings of the SI. However, while the Situationists were certainly at the center of the events, and even helped maintain barricades, they neither instigated nor controlled events. Nor, it should be mentioned, did the SI attempt to seize the banks, the media, or any other centers of state power. Instead, the SI spent almost all their efforts on the production and distribution of texts. In the midst of the revolution, the SI's position in relation to the masses of workers and students was not far removed from their position before the insurrection. In essence, they remained one competing voice among many, and their positions, even to the extent that they were understood, were not readily taken up and shaped into any coherent desire by the revolutionaries. In terms of practice, the SI looked almost as if they had never left home. Barricaded in the National Pedagogic Institute, the SI, along with the Enragés and others, continued to produce a mountain of texts that are almost indistinguishable from previous SI critiques and calls to action.

In his article "Aesthetics and Resistance: Totality Reconsidered," Stewart Home underscores what contemporary critics might do well to characterize as the SI's strangely quietist role: "coming after the start of the strikes, [the SI] had no effect on the unfolding of events! And so, while the specto-situationists have always claimed they played a key role in May events and cited them as a vindication of their theory, any informed and objective observer is unlikely to take such assertions seriously" (141). Yet, even in the face of accounts such as Home's, the SI and many critics still locate the SI's value in its seamless relation to practice, its ability to unite theory and action.

At best, the events of ' 68 provided the SI an opportunity to reach a larger audience at a volatile point, but they didn't fundamentally alter its role. In essence, the SI merely intensified its efforts to present an alternative that, given the social upheaval, had a slightly better chance to to find an audience that could hear what the SI had been advocating all along.

That the Situationists failed in " 68 is not surprising. Consider that the Situationists were not simply in favor of a revolution that would shift power into the hands of the disenfranchised. Rather, they hoped for a revolution that would not only actualize a shift in power, but transform the processes of power itself. The SI was advocating a revolution that operated totally outside the alienated forms of the spectacle. Certainly the SI's endorsement of the worker's occupation of the factories would seem to align their theory with a practical politics. However, for the revolution to have 
succeeded in the SI's terms, individuals would have had to actualize a complete transformation. Just as in the pre-68 days, the SI was still calling for the development of alternative forms of subjectivity and social organization that would transform the very roots of how individuals constituted themselves as subjects within and against the spectacular society that had produced them. As if this were not enough, members of the SI had no clear conception of how to effect such a change, and they could give no more than hints of what such a change might look like. It would be a constructed situation, which only select members of the SI had experienced in any form that could be articulated. It would be something like the maps of psychogeography, or the détourned pages of the SI journal. It would be something that no one had ever seen before.

\section{The Other Situationist Moment: Guy Debord's Memoires}

Guy Debord's Memoires is a strange book, and I chose to end with this work because it provides one of the most powerful examples of Situationist theory. Memoires is a tenuous, difficult, and utopian book. Almost predating the SI itself, and recording a history that fixes the origins of the SI in the Letterist movement, it is a thoroughly theoretical exercise that attempts to preform and intimate the sort of sense that SI would devote its entire project to conceptualizing and realizing. But Memories does not fit easily with our notion of an activist SI, and it is often dismissed as an early transitional work with few implications or uses for our contemporary moment. In fact, the only two critics to give the book much serious attention have been Greil Marcus and Len Bracken. However, Memoires is precisely an example of both the theoretical aspects of the SI our current reception occludes and a demonstration of theory's potential to create new senses. In short, it is a book that might most effectively intervene in our current debates about theory and practice.

One might object that Memoires is not an example of theory at all since it is usually considered an art object and associated more with the specifically art-oriented projects of Letterism. To this potential objection there are at least two responses. First, much like any theory, Memoires is based on a concept (here that concept is détournement). As such, we might most usefully think of it as a theoretical text that abandons traditional forms of argumentative demonstration in favor of performance. Second, one might pause before mounting too dogmatic a defense of the line between the categories of theory and art. After all, critics like Adorno often characterize the ends of both in remarkably similar terms — both are spaces for alternative thought in the context of one-dimensional worlds.

Memoires was written, or rather assembled, by Guy Debord and Asger Jorn in 1957. Debord himself often referred to Memoires as an antibook, and the original edition was bound in sandpaper, that it might destroy other books. The text is entirely composed of fragments taken from other texts: photographs, advertisements, comic strips, poetry, novels, philosophy, 
pornography, architectural diagrams, newspapers, military histories, wood block engravings, travel books, etc. Each page presents a collage of such materials connected or effaced by Jorn's structures portantes, lines or amorphous painted shapes that mediate the relationships between the fragments. The combination of Jorn's lines and Debord's collages creates a kind of hybrid between the strategies of détournement and dérive, thus approaching culture as a dérive over the face of the spectacle itself.

At its most literal level, Memoires is a history of Debord's years in the Letterist International, the precursor of the Situationist movement. In a rare exegesis of the book in On the Passage of a Few People Through a Rather Brief Moment in Time, Greil Marcus explains that

Memoires is divided into three parts. There is "June 1952" when Hurlements en Faveur de Sade, Debord's first film, was premiered, and he and Wolman first conceived the "Letterist International" as a secret tendency within Isidore Isou's Letterist movement, the postwar Parisian neo-dada band Debord and Wolman were then part of; "December 1952," when the LI, having announced itself in late October with leaflets denouncing a Charlie Chaplin press conference at the Ritz, formally established itself, laying down its statutes (taking goals for granted and, like the authors of the Constitution of the United States, concentrating on prohibitions and penalties); and "September 1953," when the group first began to come apart ("the dirt is gone!" announces a loud page in Memoires, the phrase, taken from an ad for a detergent, signifying that the LI had purified itself of microbes and viruses, of frauds and careerists). (128)

However, what is most interesting in the text is not its ostensible content, a literal, intelligible history, or its status as a founding text, but the way in which this organizational principal is undercut, even thwarted, by the fragments that are brought together presumably to tell that very story.

Ostensibly a history, it becomes a work that questions the immediate possibility of that project by presenting that history from the perspective of an as yet unrealized Situationist future. In Lipstick Traces Marcus explains that "as a memoir, Debord's book was also a prophesy. To follow its story one needed information Debord withheld - even the words 'L'Internationale Lettriste,' which never appeared. But one also needed the ability to imagine a reinvented world . . . a new, 'situationist' civilization, shared by millions, finally covering the globe" (164). Without the realization of that world, Memoires remains for us something that "would be experienced not as things at all, but as possibilities" (166).

To understand Memoires, and to argue for its absolute relevance to our own moment, I want to begin by invoking Debord's concept of the spectacle. As anyone who has read The Society of the Spectacle will remember, Debord states that "the spectacle is NOT a collection of images; rather it is a social relationship between people that is mediated by images" (12).

Debord isn't so much taking on the prevalence of the image itself as he is the 
particular form of mediation images constitute. For Debord, the spectacle is akin to Adorno's concept of the culture industry or Jameson's culturalized horizon. The images (TV, film, advertisements, etc.) are one-way identic communications that provide no possibility for a dialectical engagement or response. Each individual subject is silenced, forced to absorb the instrumental meanings of this totalizing system. As Debord puts this, "by means of the spectacle, the ruling order discourses endlessly upon itself in an uninterrupted monologue of self-praise" (19).

If Debord had not so clearly formulated these concepts during the creation of Memoires, they nonetheless animate the book, which is composed of fragments of the spectacle itself. As early as the Letterist International, Debord was negatively gesturing at the spectacle in the concept of détournement. The critique that animates this concept is one of cooption. To produce new works of art within the traditional categories means playing by the rules, being subsumed under those spectacular discourses. On the other hand, to conduct terrorist raids on the particulars of those discourses and liberate the particulars of those works holds the potential of creating revolutionary sense and desire. The images that perfected separation and political impotence could now assume nonidentic meanings, meanings that allowed one to both construct a critique and imagine a reinvented world.

To take Debord's project in terms of Adorno, Memoires is the creation of an autonomous artwork. The use of détournement shifts the emphasis to the nonidentic possibilities of the given collage elements. As a history it must, as Adorno would approve, fail, since the collaged particulars are always outstripping their function, never content to carry on a single, intelligible meaning. And yet, in Adorno's sense, it is also a unique example of enigmatic political commitment within the horizon of postmodernism, for Memoires is a profoundly political work, though not in any readily instrumentalizable register. Though I don't have the space to execute a cover to cover reading of Memoires, I would like to look closely at both its first and final pages. These pages are far more spar than many of the collages in the book, but they both highlight the tense relationships of form that animate the entire work.

The first line of Memoires (reading right to left, top to bottom, a convention the book doesn't impose) is a fragment of two sentences: "A memory of you? Yes, I want." Though the reader knows, from the title page, that this sentence has been ripped out of its original context, there is no indication of its original source. Thus it is not identical with any subject. Instead, this fragment invokes the concepts of memory and desire without specific objects. One of Jorn's lines carries the eyes from this fragment to another, in the middle of the page, which reads "it is a subject profoundly soaked in alcohol." Jorn's line spreads out into a blob just above this fragment, creating a block that puts the emphasis on this second fragment. Whatever the subject or object of this memory or desire, it is to be taken in terms intoxication, both literally and metaphorically. 
The second line of Memoires, "of lights, of shadows, of figures," underscores the indeterminacy of the elements of the text. Literally, it invokes a play of the identic and nonidentic. It suggests that each fragment could be read in terms of its original context or colloquial meaning, but that these will shift into shadow or light, constitute different figures depending on how they are read. Though the fragments may constitute recognizable figures at points, they will do so only transiently. Again, another line of Jorn's descends from this fragment, crossing others, and trailing off at the page's final deceleration: "Listen well, I will, all the same, represent these events and explain the considerations." This line gestures at the totality of the work as the literal history that Marcus reduces it to, but the emphasis is not with this line. At best, it is an ironic gesture at the failed totality of the work, a marker of the traditional desire for wholeness and understanding that the book undercuts. It isn't that history is not present, but it has become a figure that slips in and out in the play of light and shadow. In short Memoires does not present a totalizing climax, a point where the reader could make sense in the mode this fragment suggests. Rather, Jorn's line takes this desire and holds it in tension with other fragments and their gestures towards the nonidentic.

The emphasis on the right side of the page rests in the middle, at the crossings of lines that accumulate into another shape. Here, two fragments exist close to one another: "it is for you" over "full of discord and dread." The "you" of this first fragment is wonderfully ambiguous. In its original context no doubt it referred to a specific individual. However, it now enters into the play of light and shadow, suggesting the reader of Memoires, the speaker or addressee of the first fragment, the mysterious Barbra of the fragment further up the page, or even the speaker of the final line of the page. Resonating with this very play, the fragment below, "full of discord and dread," associates the asubjective, nonidentic confusion of the speaker and referent of this ambiguous "you." Mirroring these three middle fragments, the left side of the page contains two other fragments: "people observe the thresholds of silence" and "this curious system of narrative," which also gesture at the construction of the work itself, calling into question the very possibility of it speaking to anyone intelligibly, but the emphasis is not on these fragments, as Jorn's lines begin at them as almost nothing and move toward the right half of the page. This curious narrative is not something just different, but something that leads to the discord and dread of nonidentic becomings.

I would not say that this is the only possible, or even the best, reading of the page - the play of the fragments and lines invites multiple readings, and these pages are transformed by the pages that follow, by the resonances the book creates as it is read. However, I would resist the temptation to reduce these fragments to an intelligible history. Looked at closely, that history slips in and out, and the fragments themselves always destabilize or overreach their identic roles in such a narration. As the 
fragments enter into becomings with one another, such a total organizing structure can only fail. However, at the level of the aesthetic, it is this failure that constitutes Memoires as a political moment. To reduce Memoires to an intelligible history as the founding moment of the SI separates it from its active powers, reinscribing it within the spectacle. Such representations of it are less than attentive to the literal force field of antagonisms it creates.

In Adorno's sense, Memoires is political to the extent that it breaks up the monolithic discourse of the spectacle and its powers of identic thought. However, this is not politics in the activist sense we have come to value through our fear of anything that might be labeled, however speciously, quietist. As Adorno explains in his essay "Commitment,"

it is not the office of art to spotlight alternatives, but to resist by its form alone the course of the world, which permanently puts a pistol to men's heads. In fact, as soon as committed works of art do instigate decisions at their own level, the decisions themselves become interchangeable . . the work of art becomes an appeal to subjects, because it is itself nothing other than a deceleration by a subject of his own choice or failure to choose. (304)

Like Adorno's committed work of art, Memoires resists an easy translation into a practical choice. Rather, its form gestures at an alternative engagement with the materials of the spectacle. In this it does rupture the discourse of the spectacle, but it does so by creating the sense of a future that has not been realized, that, as Marcus points out, forces one to think from the perspective of a Situationist world that does not exist. In short, this is a project that exists only as theory. How, exactly, would one translate this sense into an activist practice? Neither Memoires nor later Situationist writings or practices answer this question. However, this fact should not tempt us to label this a quietist work. To push Adorno's metaphor, the space created by a book like Memoires allows us to take the gun from our heads, if only for a moment. Yet, within that moment, there is the chance to imagine a world otherwise, and that possibility surely plays a role in developing the desire necessary to someday realize such a world, or, at the least, it creates a critical difference which questions the one-dimensional sense that coordinates our spectacular lives. The relative neglect of Memoires underscores the difficulty cultural critics have when the concepts of a work cannot be readily aligned with a political project. If critics invoke the Debord of ' 68 as an example of heroic activism, they all but suppress the moment of Memoires where theory is the only expression possible.

The final page of Memoires is composed of one fragment and a simple series of Jorn's painted lines. The fragment reads "I wanted to speak the beautiful language of my century." This fragment, rife with irony, marks an alterian desire. The beautiful language of traditional art, the endless discourse of the spectacle, all that is certainly invoked in this statement. But, more than that, to make it beautiful in Debord's sense requires that this statement shudder at the spectacle. Underneath this fragment, in red, the 
color associated with the most intense collages of the text, the curving lines invoke motions culminating in an amorphous shape, perhaps the desires of the text itself centrifugally creating a kind of critical mass. If Memoires is more than a history, it is less than a political program, and this is precisely its success. What is a practical political program, even an oppositional program, but an intelligible choice already available to the extent that it is articulate? Memoires lives on because it is inarticulate, its power and potential indexed by the silence of the critics.

\section{Works Cited}

Adorno, Theodor. "Commitment." The Essential Frankfurt School Reader. Trans. Francis McDonagh. Eds. Andrew Arato and Eike Gebhardt. New York: Urizen, 1978. 300-318.

- - - Negative Dialectics. Trans. E. B. Ashton. New York: Seabury, 1973. Bathrick, David. "Cultural Studies." Introduction to Scholarship in Modern Languages and Literatures. Ed. Joseph Gibaldi. New York: MLA, 1992. 320-43.

Bérubé, Michael. The Employment of English: Theory, Jobs, and the Future of Literary Studies. New York: New York UP, 1998.

Best, Steven, and Douglas Kellner. Postmodern Theory: Critical Interrogations. New York: Guilford, 1991.

Blazwick, Iwona. An Endless Adventure . . . An Endless Passion . . . An

Endless Banquet: A Situationist Scrapbook. London: Verso, 1989.

Bracken, Len. Guy Debord: Revolutionary. Venice: Feral, 1997.

Clark, T. J. and Donald Nicholson-Smith. "Why Art Can't Kill the

Situationist International.” October 79 (1997): 15-31.

Davis, Robert Con, and Ronald Schleifer, eds. Contemporary Literary

Criticism: Literary and Cultural Studies. New York: Longman, 1994.

Debord, Guy. The Society of the Spectacle. Trans. Donald Nicholson-Smith. New York: Zone, 1994.

Debord, Guy, and Asger Jorn. Memoires. Paris: Jean-Jacques Pauvert aux Belles Lettres, 1993.

Eagleton, Terry. The Illusions of Postmodernism. Oxford: Blackwell, 1996. Home, Stewart, ed. What is Situationism?. London: AK, 1996.

Internationale Situationniste. "Definitions." International Situationniste:

1958-69. Amsterdam: Van Gennep, 1972.

Knabb, Ken, ed. Situationist International Anthology. Trans. Ken Knabb.

Berkeley: Bureau of Public Secrets, 1989

Marcus, Greil. Lipstick Traces: A Secret History of the Twentieth Century. Cambridge: Harvard UP, 1989.

- - - "Guy Debord's Memoires: A Situationist Primer." On the Passage of a Few People Through a Rather Brief Moment in Time. Ed.

Elisabeth Sussman. Cambridge: MIT UP, 1989. 
McDonough, Thomas F. "Rereading Debord, Rereading the Situationists." October 79 (1997): 1-14.

Molins, Miquel. Forward. Situationists: Art, Politics, Urbanism. Eds. Libero Andreotti and Xavier Costa. Barcelona: Museu D’Art Contemporani, 1996.

Plant, Sadie. The Most Radical Gesture: The Situationist International in a Postmodern Age. London: Routledge, 1992.

Ross, Andrew. "The Rock 'n' Roll Ghost.” October 50 (1989): 108-17.

Sadler, Simon. The Situationist City. Cambridge: MIT UP, 1998.

Trembath, Paul. "Reactivating Deleuze: Critical Affects after Cultural Materialism." Postmodern Culture 7.3 (1997). Avail url: http:// muse.jhu.edu/journals/postmodern_culture/v007/7.3r_trembath.html

Wurtzel, Elizabeth. Bitch: In Praise of Difficult Women. New York: Doubleday, 1998. 